\title{
Estratégias agroecológicas para a segurança alimentar em ambientes de montanha em Teresópolis - RJ (Brasil)
}

\author{
Hugo de Souza CERQUEIRA ${ }^{1}$, Renato Linhares de ASSIS $^{2 *}$, Lucia Helena Maria de ALMEIDA ${ }^{3}$, \\ José Guilherme Marinho GUERRA², Adriana Maria de AQUINO² \\ ${ }^{1}$ Associação Agroecológica de Teresópolis, Teresópolis, RJ, Brasil. \\ ${ }^{2}$ Embrapa Agrobiologia, Seropédica, RJ, Brasil. \\ ${ }^{3}$ Instituto de Agronomia, Universidade Federal Rural do Rio de Janeiro, Seropédica, RJ, Brasil. \\ E-mail:renato.assis@embrapa.br
}

\begin{abstract}
Recebido em maio/2018; Aceito em julho/2018.
RESUMO:O estudo foi realizado com agricultores vinculados a Associação Agroecológica de Teresópolis (AAT), visando formular e avaliar de forma participativa propostas agroecológicas. A produção agrícola orgânica familiar analisada tem forte aspecto cultural, notadamente na decisão do que plantar, considerando não apenas a demanda de mercado, mas também hábitos alimentares das famílias agricultoras. Assim, os diferentes materiais genéticos avaliados possibilitaram maior diversificação dos sistemas de produção envolvidos nas ações de troca de saberes, e a dinâmica estabelecida fortaleceu as relações agricultor-agricultor, potencializando o processo de construção e apropriação de conhecimentos. A estratégia de mercado de feira local permitiu um rápido escoamento da produção e estabelecer diálogo agricultor-consumidor com o intercâmbio de saberes culinários que reforçaram a Segurança Alimentar e Nutricional de ambos com "novos" produtos e receitas.
\end{abstract}

Palavras-chave: segurança alimentar, pesquisa participativa, transição agroecológica.

\section{Agroecological strategies for food security in mountain environments in Teresópolis - RJ (Brazil)}

\begin{abstract}
The study was carried out with farmers associated with the Associação Agroecológica de Teresópolis (AAT), aiming to formulate and evaluate agroecological proposals through a participative method. The family-based organic agricultural production analysed has a strong cultural aspect, notably the decision of what to plant, taking into account not only the market demand, but also eating habits of the farmer families. As such, the different genetic material evaluated allowed greater diversification of the production systems involved in the actions of exchange of flavors, and the established dynamic strengthened farmer-farmer relations, potentializing the process of building and appropriation of knowledge. The local market fair strategy allowed a quick distribution of the production and established a farmer-consumer dialogue with the exchange of culinary knowledge which strengthen Food and Nutritional Security of both with "new" products and recipes.
\end{abstract}

Keywords: food security, participative research, agroecological transition.

\section{INTRODUÇÃO}

As montanhas ocupam, aproximadamente, a quarta parte da superfície terrestre e são a base direta de sustento de quase $12 \%$ da população mundial, proporcionando bens e serviços básicos para mais de $50 \%$ da humanidade (NAÇÕES UNIDAS, 2007).

Devido as suas dimensões verticais, as montanhas criam gradientes de temperatura, precipitação e insolação. Uma determinada encosta pode reunir diversos sistemas climáticos, cada um representando um microcosmo de uma diversidade ainda mais ampla de habitat, apresentando assim grande variedade de sistemas ecológicos complexos e interrelacionados (NAÇÕES UNIDAS, 1992). Tudo isto contribui para a riqueza de espécies da fauna e da flora, como também para o grande número de espécies endêmicas encontradas nas montanhas (MARTINELLI, 2007). Além disso, as regiões montanhosas fornecem recursos fundamentais para o ser humano, como água, energia, minérios, produtos florestais e agrícolas (NAÇÕES UNIDAS, 1992).
No que se refere à atividade agropecuária desenvolvida em montanhas, verifica-se especificidades inerentes à fragilidade desses ambientes (FAO, 2002). A dificuldade de acesso proporcionada pela topografia; susceptibilidade à variações climáticas; pouca profundidade do solo que facilita a ocorrência de deslizamentos de terras e processos erosivos; oscilações de temperatura entre os períodos diurno e noturno, são algumas limitações da produção nesses ambientes, que influenciam na comercialização e no desenvolvimento local. Mas, por outro lado, o manejo adequado desses ambientes proporciona produção de gêneros alimentícios diversificados e característicos em função de microclimas locais.

Para o manejo adequado dos agroecossistemas, entende-se que as práticas agroecológicas devem ser a base tecnológica apropriada, aliado à necessidade de propostas de promoção do desenvolvimento rural que articulem, a partir de métodos participativos, desde sempre que os agricultores envolvidos se apropriem da noção de território e dos conhecimentos e processos agroecológicos, de forma a que estes tenham autonomia na busca de caminhos que viabilizem melhores 
condições de permanência e prática da agricultura nas montanhas.

Assim, conforme coloca Abramovay (2006), perceber que o mundo rural está além do entendimento dos processos ligados a produção agrícola, e que a sua compreensão requer a análise das interações existentes entre os diferentes atores sociais envolvidos. Para o autor, o processo de construção da noção de território traz a necessidade de compreender de como se dá a relação entre os sistemas sociais e ecológicos, e de que forma os recursos disponíveis estão sendo utilizados na sua organização produtiva.

No Brasil não existem políticas públicas específicas para o desenvolvimento sustentável de regiões montanhosas (NETTO, 2013). Além disso, restrições de atividades relacionadas às áreas de preservação permanente (APPs), que são determinadas pelo Código Florestal, são mais presentes nos ambientes de montanha (NETTO et al., 2011). No estado do Rio de Janeiro, esta realidade nacional, também se faz presente, notadamente na Região Serrana Fluminense que, em acréscimo, alia a forte atividade agrícola à presença de importantes Unidades de Conservação Ambiental. Nesta região verifica-se que políticas públicas são implementadas com foco ambiental e agrícola sem interação efetiva, e sem considerar as especificidades dos ambientes de montanha que a constituem e das populações que neles habitam e produzem.

Os produtos hortícolas distinguem-se nesse processo regional, à medida que as hortaliças consumidas pelos cerca de 10 milhões de habitantes da Região Metropolitana da cidade do Rio de Janeiro, têm origem principalmente na Região Serrana Fluminense, onde o modelo agrícola predominantemente adotado baseia-se no uso intensivo dos solos, de agrotóxicos e fertilizantes sintéticos. Em contraposição a este quadro, esta mesma região é, há mais de 30 anos, a principal fornecedora de produtos orgânicos no estado do Rio de Janeiro, com diversas organizações de agricultores que seguem o manejo orgânico (CERQUEIRA, 2016).

No início da atual década, este quadro relacionado à vulnerabilidade ambiental da agricultura na Região Serrana Fluminense, foi mais do que potencializado com as fortes chuvas que acometeram a região no período de janeiro de 2011, quando, de acordo com Busch; Amorim (2011), durante os dias 11 e 12 de janeiro de 2011 a região foi gravemente atingida por intensa precipitação pluviométrica, provocando inúmeros deslizamentos de terra e inundações repentinas, que ocasionaram a morte de mais de novecentas pessoas, deixando centenas de desaparecidos, desabrigando e desalojando mais de 20.000 habitantes nas zonas urbanas e rurais. Os municípios fortemente afetados foram Nova Friburgo, Teresópolis, Petrópolis, São José do Vale do Rio Preto, Bom Jardim, Sumidouro e Areal. Segundo dados do Instituto Nacional de Meteorologia, o volume de precipitação alcançou o índice de $130 \mathrm{~mm}$ por dia, quando o esperado para a época do ano seria $60 \mathrm{~mm}$. Alguns especialistas avaliaram em alguns pontos que o índice deve ter ultrapassado $200 \mathrm{~mm}$. As chamadas "cabeças d'água" formaram-se na interseção dos municípios de Nova Friburgo, Teresópolis, Sumidouro e Petrópolis, e não há registros da pluviometria nesses locais. Esse fenômeno foi descrito pelo governo federal como o pior desastre ambiental da história brasileira e pela ONU como o oitavo pior da história mundial.
Foram registradas perdas nas áreas agrícolas em decorrência de soterramento pela lama das enxurradas e terra do deslizamento de encostas. Em várias áreas ocorreram o tombamento de plantas, a lixiviação de fertilizantes e a erosão laminar e profunda de solos. Muitos agricultores ficaram impedidos de se deslocar até as áreas de produção. Muitos perderam o ponto de colheita tornando o produto impróprio para o comércio. Aqueles que conseguiram colher não tiveram como escoar a produção. Em consequência ocorreu uma significativa redução de produção e produtividade em todas as atividades exploradas na região.

A população rural da região, que já sofria as consequências da insustentabilidade do modelo agrícola predominante, teve sua situação agravada pela catástrofe climática. Na ocasião, em decorrência do grande volume de chuva, ocorreu saturação dos solos, transbordamento de rios e deslizamentos de encostas, juntamente com destruição de moradias, plantações, pontes e estradas. A tragédia causou alteração geográfica da área afetada com a mudança do curso de rios e córregos (BUSCH; AMORIM, 2011).

Este quadro de falta de estradas para circulação de mercadorias, aliado ao fato de os sistemas de produção predominantes terem como foco o monocultivo de hortaliças específicas, determinou que muitas famílias passassem por restrições alimentares e financeiras, uma vez que sua produção se perdeu ou não teve condição de ser escoada, ao mesmo tempo que sofreram com o desabastecimento local. Assim, questões relacionadas à precariedade da Segurança Alimentar e Nutricional, ficaram evidentes com o estabelecimento do quadro contraditório de agricultores com dificuldades de obter o que comer.

Destarte, este artigo tem como objetivo analisar a dinâmica do processo de inovação tecnológica junto aos sistemas de produção dos agricultores orgânicos vinculados a Associação Agroecológica de Teresópolis (AAT), decorrente da promoção de práticas de uso conservacionista dos solos e de redução das fragilidades das unidades de produção, quanto à biodiversidade dos cultivos e dependência por insumos externos, visando a transição agroecológica.

\section{MATERIAL E MÉTODOS}

Foram estabelecidas diferentes estratégias agroecológicas voltadas à segurança alimentar, desde o início do ano de 2014 até o final de 2016, junto aos agricultores (50) vinculados a Associação Agroecológica de Teresópolis (AAT), que congrega agricultores vinculados a três sistemas participativos de garantia (SPG) da conformidade orgânica (São José do Vale do Rio Preto, Teresópolis/Sumidouro e Guapimirim), vinculados a Associação de Agricultores Biológicos do Estado do Rio de Janeiro (ABIO). As ações foram desenvolvidas prioritariamente junto aos agricultores (36) do SPG de Teresópolis/Sumidouro, e teve por base as estratégias agroecológicas priorizadas pelos agricultores para serem desenvolvidas no âmbito do projeto: "Estratégias Agroecológicas para a Segurança Alimentar em Ambientes de Montanha", coordenado pelo Núcleo de Pesquisa e Treinamento para Agricultores (NPTA) da Região Serrana Fluminense, da Empresa Brasileira de Pesquisa Agropecuária (Embrapa).

Considerando que a promoção de estratégias agroecológicas se baseia na adaptação da base produtiva às condições ambientais, bem como na adaptação e utilização de 
métodos que possibilitem o envolvimento dos agricultores na avaliação local das soluções desenvolvidas pela pesquisa, foram estabelecidos grupos de interesse. No âmbito desses grupos buscou-se envolver os agricultores na formulação e avaliação de possíveis encaminhamentos tecnológicos, nas temáticas priorizadas, através da implantação e condução de unidades de experimentação participativa e promoção de oficinas com conteúdo teórico e prático.

Para mobilização dos grupos de interesse, atividade de troca de saberes científicos e cotidianos, para sensibilização e motivação dos agricultores, foi inicialmente realizada no Sistema Integrado de Produção Agroecológica (SIPA). Conhecido como Fazendinha Agroecológica Km 47, o SIPA é um espaço físico, criado no município de Seropédica, Baixada Fluminense, no ano de 1993, com gestão compartilhada em regime de parceria envolvendo o Centro Nacional de Pesquisa de Agrobiologia da Embrapa (Embrapa Agrobiologia), a Universidade Federal Rural do Rio de Janeiro (UFRuralRJ) e a Empresa de Pesquisa Agropecuária do Estado do Rio de Janeiro (Pesagro-Rio), e representa um polo para o desenvolvimento e socialização de conhecimentos sobre agroecologia, em consonância com os princípios e normas técnicas vigentes da agricultura orgânica, adotando abordagens sistêmicas e integrando cultivos diversificados e pecuária. O preparo e condução das áreas das unidades de experimentação participativa foram sempre realizados pelos agricultores responsáveis pelas unidades de produção onde estas estavam situadas, com apoio de mutirões, nos momentos das diferentes dinâmicas de grupo realizadas para promoção de diálogo agricultor-agricultor e agricultor-técnico.

Os resultados dessas ações foram avaliados em 2016 e sistematizados de modo a entender como ocorreu a internalização dos processos pelos agricultores em seus sistemas de produção.

O processo de troca de saberes científicos e cotidianos realizado na Fazendinha Agroecológica km 47 (Figura 1), ocorreu com base em dinâmica em que se buscou levantar com os agricultores, baseado no que foi visto e discutido previamente no local, possibilidades de temas para ações de construção coletiva de conhecimentos, a serem desenvolvidas nos sistemas de produção vinculados a AAT. Foi então dado destaque para a necessidade de resgate e intercâmbio de cultivares tradicionais, e estratégias de produção, preservação e distribuição de sementes e propágulos de adubos verdes, raízes e tubérculos comestíveis, de modo a aumentar a diversificação dos cultivos e produtos, para o mercado e base alimentar das famílias agricultoras. Esses temas foram prioritariamente tratados nas unidades de experimentação participativa, enquanto que outros temas destacados: inimigos naturais, caldas alternativas e agentes de biocontrole, manejo da fertilidade do solo, e plantas alimentícias não convencionais - PANC, foram tratados em oficinas com conteúdo teórico e prático.

Assim, tendo por base as estratégias agroecológicas priorizadas com os grupos de agricultores, estabeleceu-se como eixo central desenvolver sistemas de cultivos que possibilitassem o máximo de cobertura do solo nas diferentes épocas do ano, assim como gerar maior diversidade e abundância de alimentos fortalecendo a segurança alimentar e nutricional das famílias agricultoras, atividades de implantação e condução coletiva de áreas de multiplicação de materiais genético de interesse geral e conduziu-se, em Teresópolis, unidade de experimentação participativa em área em pousio de seis anos, vizinha a unidade de produção orgânica de associado da AAT, pertencente a agricultor convencional que iniciou então processo de transição agroecológica (Figura 2).

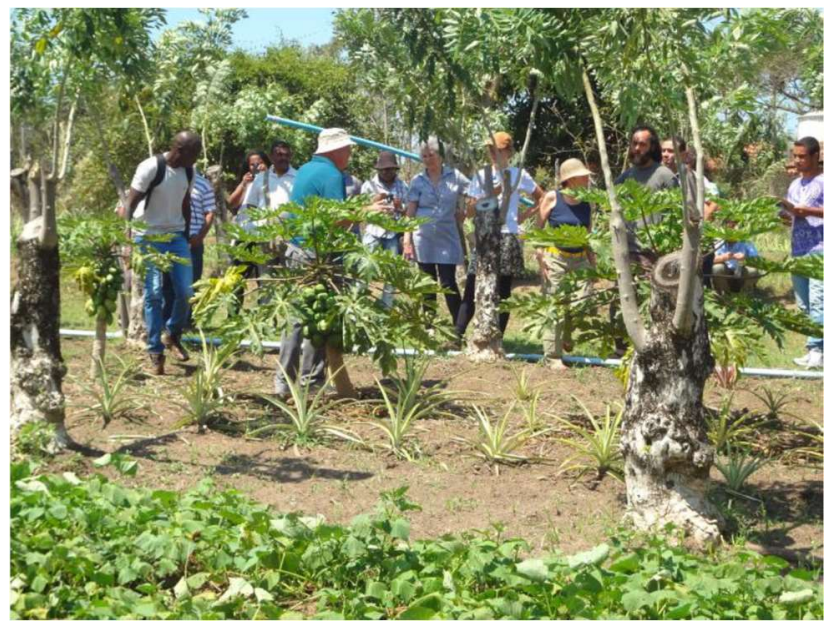

Figura 1. Visita técnica ao Sistema Integrado de Produção Agroecológica (SIPA), conhecido como Fazendinha Agroecológica Km 47: estratégia inicial para mobilização dos agricultores para troca de saberes científicos e cotidianos. Foto: Renato Linhares de Assis. Figure 1. Field trip to the Integrated Agroecological Production System (SIPA in Portuguese), known as Fazendinha Agroecológica $\mathrm{Km}$ 47: initial strategy to mobilize farmers to exchange scientific and local knowledge. Photo: Renato Linhares de Assis.

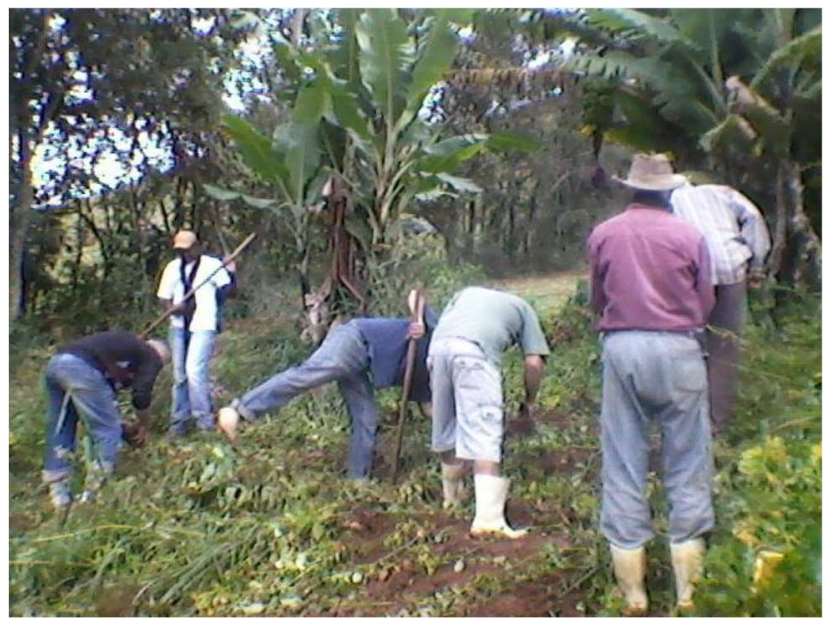

Figura 2. Ação coletiva de condução de unidade de experimentação participativa visando a transição agroecológica de unidade de produção convencional. Foto: Hugo de Souza Cerqueira.

Figure 2. Collective action for conducting participatory experimentation unit aiming agroecological transition of the conventional production unit. Photo: Hugo de Souza Cerqueira.

A área da unidade de experimentação participativa de agricultor convencional, em que se iniciou o processo de transição agroecológica, já possuía uma abundância de matéria orgânica decorrente da vegetação nativa presente. Isso foi considerado como base inicial para implementar cultivos econômicos de interesse, bem como inserção posterior de cultivo de mistura de adubos verdes (Figura 3). Como primeiros cultivos trabalhados, procurou-se utilizar plantas de caráter mais extensivo, notadamente raízes e tubérculos, utilizando, sempre que possível, diversidade de cultivares (Figura 4) para proporcionar maior variabilidade genética e de sabores, no sistema de produção envolvido. Esses cultivos 
foram realizados em consórcio com adubos verdes, sempre que possível associando uma leguminosa com o milho, tendo esta dupla função: produção de matéria orgânica e espigas para venda de milho verde.

Ao fim de dois anos de trabalho foi possível iniciar o cultivo de hortaliças de ciclo curto, com uso mais intensivo do solo, porém mantendo o caráter de associação com os adubos verdes.

Concomitantemente, a partir da organização dos grupos de interesse com o SPG de Teresópolis/Sumidouro da ABIO, outras unidades de experimentação participativa foram implantadas e conduzidas para multiplicação de sementes e material propagativo de: adubos verdes, batata inglesa (Solanum tuberosum), batata doce (Ipomoea batatas), aipim (Manihot esculenta), inhame (Colocasia esculenta) e batata baroa (Arracacia xanthorrhiza) (Figura 5), bem como oficinas tecnológicas relacionadas a: inimigos naturais, caldas alternativas e agentes de biocontrole fitossanitário, manejo da fertilidade do solo, e plantas alimentícias não convencionais (PANC), de forma a atender outros temas de interesse levantados no processo de troca de saberes científicos e cotidianos realizado na Fazendinha Agroecológica km 47.

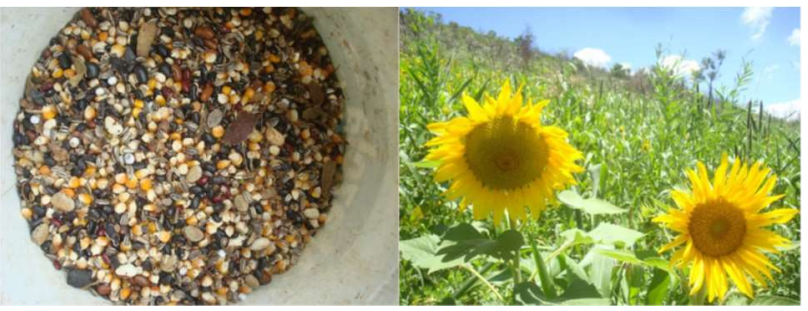

Figura 3. Cultivo de consórcio de adubos verdes a partir de mistura de sementes de: girassol (Helianthus annuus), milho (Zea mays), milheto (Pennisetum glaucum), mucuna preta (Mucuna pruriens), mucuna cinza (Mucuna cinereum), feijão de porco (Canavalia ensiformis), crotalariajuncea (Crotalaria juncea) e guandu (Cajanus cajan). Fotos: Hugo de Souza Cerqueira.

Figure 3. Cultivation of green manure consortium from a mixture of seeds of sunflower (Helianthus annuus), corn (Zea mays), pearl millet (Pennisetum glaucum), velvet bean (Mucuna pruriens), gray mucuna (Mucuna cinereum), jack bean (Canavalia ensiformis), Crotalaria juncea and pigeonpea (Cajanus cajan). Photos: Hugo de Souza Cerqueira.

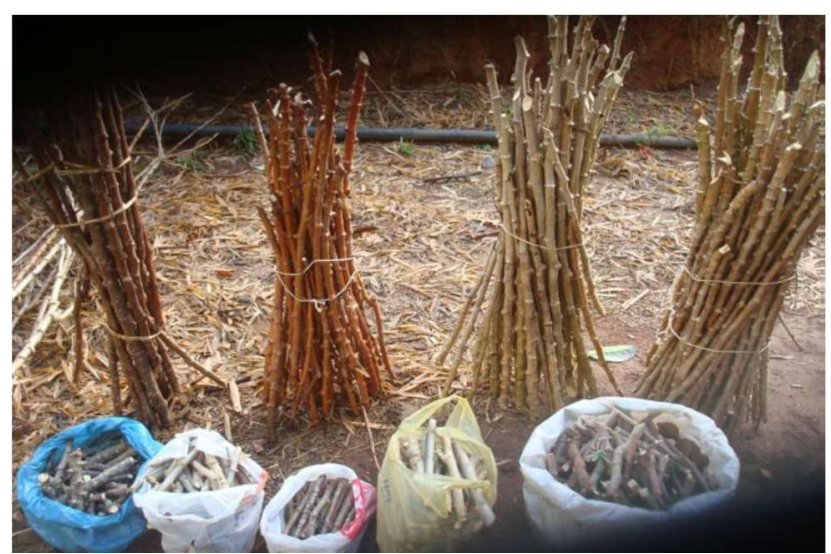

Figura 4. Cultivares (10) de aipim (Manihot esculenta) utilizadas. Foto: Hugo de Souza Cerqueira.

Figure 4. Manioc cultivars (10) (Manihot esculenta) used. Photo: Hugo de Souza Cerqueira.
O acompanhamento das atividades foi sempre reforçado nas discussões realizadas nas reuniões mensais da AAT, bem como por dinâmicas envolvendo agricultores e técnicos, no acompanhamento das unidades de experimentação participativa e oficinas tecnológicas, e as sementes e propágulos multiplicados foram intercambiados entre os agricultores, bem como passaram a fazer parte do banco de materiais propagativos da associação.

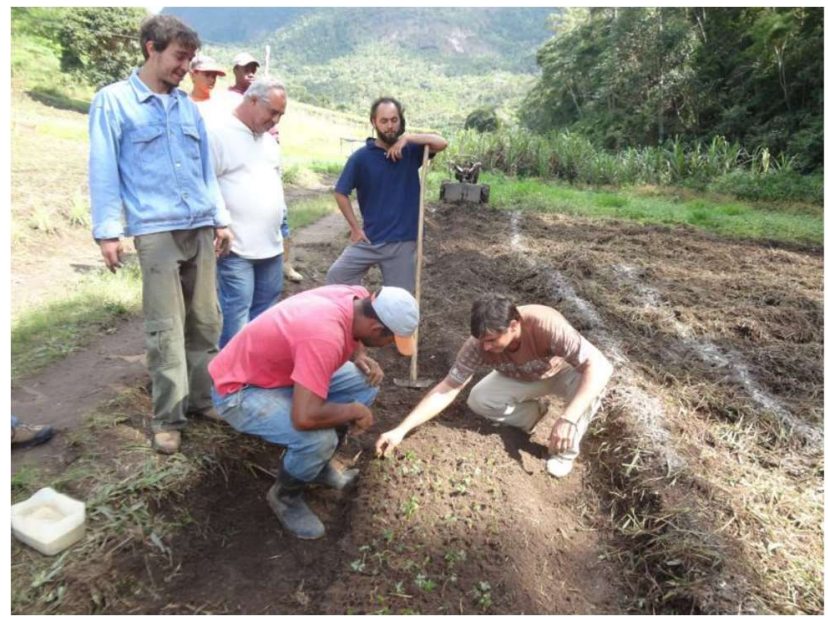

Figura 5. Implantação de unidade de experimentação participativa de produção e multiplicação de material propagativo de batata baroa (Arracacia xanthorrhizat). Foto: Renato Linhares de Assis.

Figure 5. Implementation of participatory experimentation unit for production and multiplication of Arracacia xanthorrhizat propagating material. Photo: Renato Linhares de Assis.

\section{RESULTADOS}

O agricultor, responsável pela área onde foi conduzido o trabalho de experimentação participativa, incorporou as práticas gerais da agricultura orgânica em sua unidade de produção como um todo, que passou a ser comercializada com base em estratégias diversificadas de mercado, com destaque para circuitos curtos, como feira na cidade de Teresópolis (Figura 6). Em acréscimo, incorporou a diversificação alimentar no dia-dia de sua família, melhorando sua segurança e soberania alimentar, com o consumo de produção oriunda de sua unidade produtiva.

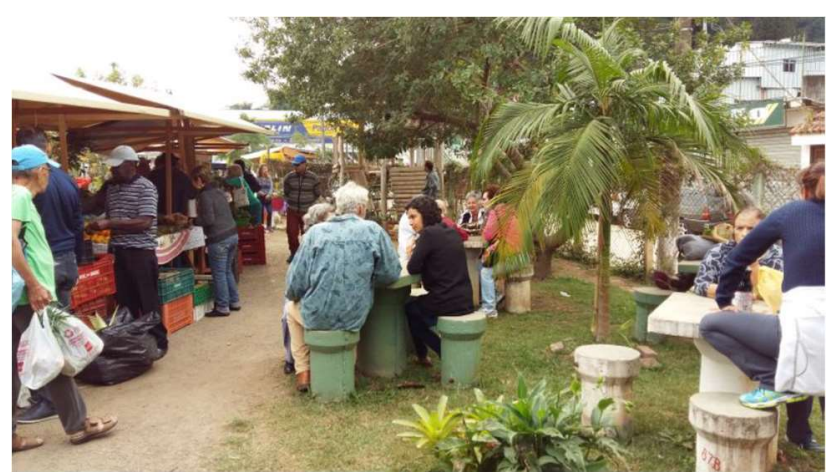

Figura 6. Feira da Associação Agroecológica de Teresópolis. Foto: Renato Linhares de Assis.

Figure 6. Associação Agroecológica de Teresópolis street market. Photo: Renato Linhares de Assis.

Os materiais genéticos introduzidos e a oficina de PANC contribuíram para uma maior diversificação dos sistemas de produção dos agricultores vinculados ao SPG da ABIO de Teresópolis/Sumidouro, diretamente envolvidos no trabalho, 
bem como indiretamente dos agricultores dos SPG de Guapimirim e de São José do Vale do Rio Preto, através da articulação agricultor-agricultor no âmbito das feiras da AAT. Essa diversificação contribuiu positivamente para a Segurança Alimentar e Nutricional tanto das famílias agricultoras como dos consumidores, através de uma maior oferta diversificada de alimentos nas bancas de comercialização das feiras da AAT, e comercializados junto ao PNAE.

$\mathrm{O}$ trabalho fortaleceu as dinâmicas e relações agricultoragricultor potencializando o processo de construção e apropriação de conhecimentos, inclusive com intercâmbio de materiais genéticos, notadamente de aipim, inhame, respectivamente com 12 e 2 materiais efetivamente apropriados e intercambiados entre os agricultores.

A incorporação do uso dos materiais genéticos de raízes, tubérculos e milho branco, não só in natura, como também através de processados como pães, bolos, curau, biscoitos e goma para tapioca, fortalecendo o resgate e construção de hábitos alimentares diversificados baseados em produtos adequados a realidade socioambiental local, indicaram caminho importante a ser trilhado para fortalecimento da soberania alimentar na Região Serrana Fluminense.

A dinâmica agricultor-agricultor favoreceu a diversificação de adubos verdes junto aos sistemas de produção onde a prática da adubação verde já era realizada, através da troca de sementes, mas a repercussão das atividades ficou praticamente restrita junto aos agricultores que já realizavam esta prática, os quais passaram a utilizar uma maior variedade de espécies. Apenas em um sistema de produção o tema foi efetivamente inserido como novidade, o qual caracterizado como neorural teve motivações ideológicas relacionadas com preocupação com a questão da sustentabilidade ambiental de sua atividade. No restante do grupo a prática foi identificada como intensiva no uso de mão de obra, o que no processo de decisão produtiva foi relevante, face a forte demanda desse recurso em função da demanda estabelecida pelo mercado de feiras, que é predominante para os agricultores vinculados a AAT.

\section{DISCUSSÃO}

Nas dinâmicas e diálogos agricultor-pesquisador, verificou-se que para melhor aceitação da prática da adubação verde pelos agricultores, teria sido necessário uma inserção da prática junto a estratégias produtivas com finalidade econômica, seja através do consórcio dos adubos verdes com plantas de interesse econômico, ou através de subprodutos, como por exemplo o uso de milho em plantio adensado para adubação verde associada à produção de mini-milho.

Esse entendimento tem por base a experiência com adubação verde na unidade de unidade de experimentação participativa de agricultor convencional, em que se iniciou processo de transição agroecológica, onde os diálogos agricultor-pesquisador indicaram que houve uma percepção favorável pelo agricultor dos benefícios dessa prática.

Porém, verificou-se que houve dificuldade de inserir o uso dos adubos verdes nas rotações de cultivo, face a pouca disponibilidade de mão de obra. Exceção foi o caso da experiência com o consórcio de milho verde com mucuna cinza, que foi considerada positiva, face a possibilidade de retorno econômico com o milho verde, associada ao benefício no cultivo subsequente de diversas hortaliças (brócolos, cenoura, alface, beterraba, cebola, cebolinha, salsa, coentro, rabanete, couve, mostarda, alho poró) para o atendimento de banca na feira da AAT, na medida em que o processo de transição agroecológica possibilitou que a acreditação do agricultor como orgânico.

É interessante ainda destacar que a inserção desse agricultor na dinâmica da agricultura orgânica ocorreu a partir de diálogo agricultor-agricultor. Este iniciado em conversa realizada com vizinho, agricultor orgânico, na cozinha da residência da família, quando a esposa questionou o marido do por que tinham uma produção agrícola tão pouco diversificada, sendo, portanto, tão dependentes da compra para aquisição de produtos para sua alimentação. Este questionamento possibilitou a inserção da unidade de experimentação participativa aqui relatada, e que enfatizou a inserção de cultivos de base alimentar - principalmente raízes e tubérculos (Figura 7).

Esse diálogo, agricultor-agricultor, saiu então "da cozinha" e foi para o campo com o efetivo envolvimento da família em questão com a dinâmica da AAT, bem como influenciando outra família agricultora que também se inseriu na dinâmica da agricultura orgânica, e continua influenciando outros vizinhos que, se não estão totalmente inseridos na dinâmica da agricultura orgânica, tem adotado práticas relacionadas ao manejo orgânico, possibilitando uma produção agrícola com uso mais racional dos recursos ambientais.

Verificou-se ainda que a inserção dessa família na dinâmica da agricultura orgânica favoreceu a inserção do filho de 24 anos no dia a dia do sistema de produção familiar, posto que este passou a trabalhar fora da unidade de produção apenas meio período durante cinco dias por semana, bem como a ser o membro da família responsável pela comercialização da produção aos sábados em feira da AAT.

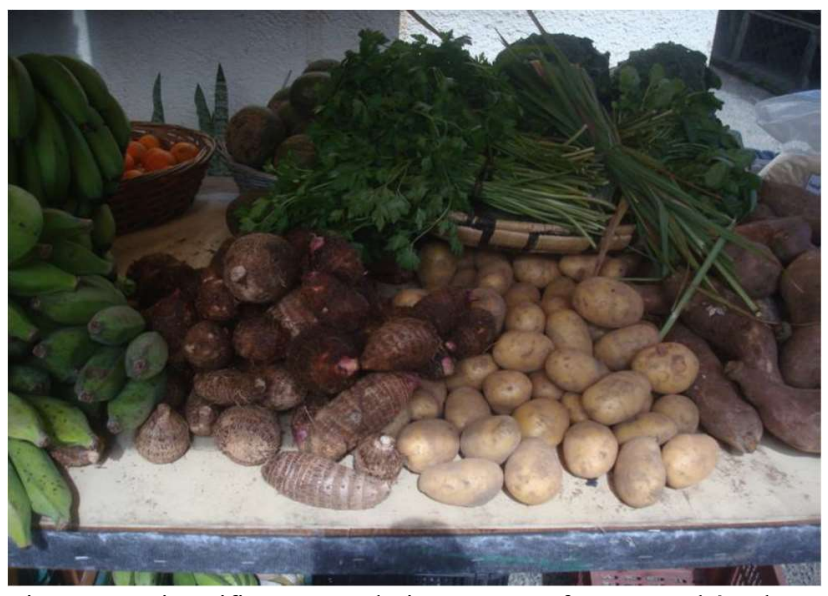

Figura 7. Diversificação produtiva, com ênfase em tubérculos e raízes, obtida em unidade familiar em que se promoveu a transição agroecológica e sua acreditação orgânica. Foto: Renato Linhares de Assis.

Figure 7. Productive diversification, with emphasis on tubers and roots, obtained in a family unit in which the agroecological transition and its organic accreditation were promoted. Photo: Renato Linhares de Assis.

\section{CONCLUSÕES}

A produção agrícola orgânica familiar na Região Serrana Fluminense tem forte aspecto cultural, notadamente na decisão do que plantar, considerando não apenas aspectos de demanda de mercado, mas também de hábitos alimentares das famílias agricultoras.

Os diferentes materiais genéticos trabalhados nas unidades de experimentação participativa possibilitaram uma maior 
diversificação dos sistemas de produção familiares dos diferentes grupos de interesse envolvidos nas ações de troca de saberes científicos e cotidianos.

A dinâmica de trabalho estabelecida fortaleceu as relações agricultor-agricultor potencializando o processo de construção e apropriação de conhecimentos, inclusive com intercâmbio de materiais genéticos.

A estratégia de mercado preferencial por cadeias curtas de comercialização, como feira local, permite um rápido escoamento de produção diversificada bem como 0 estabelecimento de diálogo agricultor-consumidor com o intercâmbio de saberes culinários que reforçam a Segurança Alimentar e Nutricional de ambos com "novos" produtos e receitas.

\section{AGRADECIMENTOS}

A Empresa Brasileira de Pesquisa Agropecuária (Embrapa) e ao Conselho Nacional de Desenvolvimento Científico e Tecnológico (CNPq) pelo apoio financeiro para a realização das atividades.

\section{REFERÊNCIAS}

ABRAMOVAY, R. Para uma teoria de estudos territoriais. 2006. Disponível

em:

$<$ http://nmd.ufsc.br/files/2011/05/Abramovay Para uma teoria_dos_estudos_territoriais.pdf $>$. Acesso em: 06 de setembro de 2017.

BUSCH, A.; AMORIM, S. A tragédia da região serrana do Rio de Janeiro em 2011: procurando respostas. ENAP: Casoteca de Gestão Pública, 2011. Disponível: $<$ http://casoteca.enap.gov.br/>. Acesso em: 29 mai. 2015 .

FAO FOOD AND AGRICULTURAL ORGANIZATION. Declaración de Adelboden sobre la Agricultura y El Desarrollo Rural Sostenibles en regiones de Montaña (ADRS-M). 2002. Disponível em $<$ http://www.fao.org/sard/common/ecg/1182/es/Adelbode nDeclaration_es.pdf $>$. Acesso em: 25 de agosto de 2010.
MARTINELLI, G. Mountain Biodiversity in Brazil. Revista Brasileira de Botânica, São Paulo, v. 30, n. 4, p. 587-597, out./dez. 2007. DOI: http://dx.doi.org/10.1590/S010084042007000400005

NAÇÕES UNIDAS. Agenda 21. Rio de Janeiro, 1992. Disponível $<$ http://www.mma.gov.br/sitio/index.php?ido=conteudo. monta\&idEstrutura $=18 \&$ idConteudo $=575 \&$ idMenu $=9065$ >. Acesso em: 25 de agosto de 2010 .

NAÇÕES UNIDAS. Desarrollo sostenible: desarrollo sostenible de las regiones montañosas. Asamblea General, 2007. Disponível em $<$ http://daccess-ddsny.un.org/doc/UNDOC/LTD/N07/628/63/PDF/N0762863 .pdf?OpenElement>. Acesso em: 02 de julho de 2010.

NETTO, A. L. Políticas públicas para o desenvolvimento rural em ambientes de montanha no Brasil e na Argentina. 2013. 183 f. Tese (Doutorado em Ciência, Tecnologia e Inovação em Agropecuária). Universidade Federal Rural do Rio de Janeiro. Seropédica, 2013.

NETTO, A., L.; AQUINO, A. M. de; ASSIS, R. L. de. Agricultura de Montanha: uma prioridade latente na agenda da pesquisa brasileiro. Brasília: Embrapa Informação Tecnológica, 2011. 75p. (Texto para Discussão, 41) Disponível em: $<$ https://www.alice.cnptia.embrapa.br/alice/bitstream/doc/ 901579/4/Texto41.pdf>. Acesso em: 15 out. 2018. 